\title{
Correction to: Thermodynamic Assessment of the In-Ni-Sb System and Predictions for Thermally Stable Contacts to InSb
}

\author{
ZHANMIN CAO, ${ }^{1,2}$ WEI XIE, ${ }^{1}$ KUNPENG WANG,${ }^{1}$ GUANGWEI DU, ${ }^{1}$ \\ and ZHIYU QIAO ${ }^{1}$ \\ 1.-State Key Laboratory of Advanced Metallurgy, School of Metallurgical and Ecological \\ Engineering, University of Science and Technology Beijing, Beijing 100083, China. 2.-e-mail: \\ zmcao@ustb.edu.cn
}

\section{Correction to:}

Journal of ELECTRONIC MATERIALS,

Vol. 42, No. 8, 2013

https://doi.org/10.1007/s11664-013-2599-7

In the original article, there are three errors in the parameters listed under $\omega(\mathrm{NiIn}):(\mathrm{Ni}, \mathrm{Va})_{0.5}(\mathrm{In}$, $\mathrm{Ni})_{0.5}$ in Table II. The corrected parameters are as follows:

${ }^{0} G_{\text {Va:In }}^{\omega}=21518.18-11.5225 T+0.5^{0} G_{\text {In }}^{\text {Tetragonal } \_\mathrm{A} 6}$

${ }^{0} L_{\mathrm{Ni}, \mathrm{Va}: \mathrm{In}}^{\omega}=-36696.83+18.568595 T$

${ }^{1} L_{\mathrm{Ni}, \mathrm{Va}: \mathrm{In}}^{\omega}=-22748.13+29.58067 T$ 